\title{
Escorregamentos rasos em São Luiz do Paraitinga (SP, Brasil) (2009-2010)
}

\author{
Shallow landslides in São Luiz do Paraitinga (SP, Brazil) (2009- \\ 2010)
}

\author{
José Eduardo Bonini, Departamento de Geografia, Universidade de São Paulo, Brasil, \\ jose.bonini@usp.br \\ (1) https://orcid.org/0000-0001-6047-0141 \\ Jurandyr Luciano Sanches Ross, Departamento de Geografia, Universidade de São Paulo, Brasil, \\ juraross@usp.br \\ (1) https://orcid.org/0000-0002-7726-2960 \\ Tiago D. Martins, Instituto das Cidades, Universidade Federal de São Paulo, Brasil, \\ td.martins@unifesp.br \\ (1) https://orcid.org/0000-0002-1213-1441 \\ Bianca Carvalho Vieira, Departamento de Geografia, Universidade de São Paulo, Brasil, \\ biancacv@usp.br \\ (1) https://orcid.org/0000-0001-7060-2830
}

Resumo: Escorregamentos e inundações estão entre as tipologias de desastres que geram os maiores danos no Brasil. No verão de 2009-2010 algumas cidades no Planalto de Paraitinga-Paraibuna (SP), dentre elas São Luiz do Paraitinga, foram atingidas por precipitações intensas que deflagraram centenas de escorregamentos e uma grande inundação. O objetivo deste artigo foi caracterizar as áreas afetadas por escorregamentos considerando aspectos geológicos, geomorfológicos e de uso da terra, tendo como área de estudo três bacias hidrográficas em São Luiz do Paraitinga com grande quantidade de registros de escorregamentos rasos. Os resultados mostraram um predomínio de vertentes embasadas por granitoides, com ângulos até $23^{\circ}$, com curvatura côncava e cobertas por pastos com terracetes de pisoteio. Os escorregamentos rasos de 2009-2010 ocorreram, sobretudo, em vertentes embasadas por rochas granitoides e migmatíticas, com ângulos entre $25^{\circ}$ e $37^{\circ}$. Estudos futuros podem avaliar a relação entre o uso da terra e os escorregamentos de 2009-2010 no Planalto de Paraitinga-Paraibuna, além de avaliações mais detalhadas sobre as propriedades dos solos e os fatores deflagradores dos escorregamentos.

Palavras-chave: Movimentos de massa; Litologia; Geomorfometria; Planalto de Paraitinga-Paraibuna; Vale do Paraíba.

\begin{abstract}
Regarding disasters, landslides and floods are the two types that causes the most damage and losses in Brazil. Some municipalities located on the Paraitinga-Paraibuna plateau were hit by intense rainfall in the 2009-2010 summer, triggering hundreds of landslides and a major flood. This article aimed to characterize the areas affected by landslides regarding geology, geomorphology and land use, having as study area three basins in São Luiz do Paraitinga with a large number of shallow landslides scars. Results show a predominance of granitoids in the area, slopes up to $23^{\circ}$, with concave curvature and covered by pastures and cattle stomping terraces. Landslides from the 2009-2010 event occurred predominantly on migmatites and granitoids areas and on slopes with angles between $25^{\circ}$ and $37^{\circ}$. Future studies can focus on the relationship between land use and the 2009-2010 landslides in the Paraitinga-Paraibuna plateau, in addition to more detailed studies of soil properties and the landslides triggering factors.
\end{abstract}

Keywords: Mass movements; Lithology; Geomorphometry; Paraitinga-Paraibuna Plateau; Paraíba Valley. 


\section{Introdução}

Entre 1900 e 2019 foram registradas mais de 23 milhões de vítimas fatais por todos os tipos de desastres naturais no mundo (EM-DAT, 2020). No Brasil, apenas entre 2012 e 2015, os prejuízos causados por seca e pelas chuvas ultrapassaram os $\mathrm{R} \$ 173,5$ bilhões (Oliveira, 2016). Em relação às inundações (não foram considerados os processos de alagamentos e enxurradas), somente entre 1991 e 2002, 34\% do total dos eventos se concentraram na região Sudeste com cerca de 1.615 ocorrências, registradas por 780 municípios (CEPED-UFSC, 2013). Esta mesma região concentra também o maior número de ocorrências de movimentos de massa no mesmo período (79,8\%), com aumento progressivo nas últimas décadas (CEPED-UFSC, 2013).

Entre as décadas de 1960 e 1990, foram registrados eventos pontuais e generalizados em diferentes unidades da federação (Barata, 1969; Costa Nunes, 1969; Jones, 1973; Bigarella et al., 1975; De Ploey, Cruz, 1979; Tatizana et al., 1987; Wolle, Hachich, 1989; Massad et al., 2000; CEPED-UFSC, 2013) e entre os anos de 2008 e 2014, o Brasil registrou os eventos climáticos mais catastróficos da sua história, dentre eles os eventos no estado de Santa Catarina (Vianna, 2009), no município de São Luiz do Paraitinga em São Paulo (Brollo et al., 2010; Oliveira et al., 2018), no litoral do Paraná (Silveira et al., 2013; Martins et al., 2017) e na região serrana no Rio de Janeiro (Coelho-Netto et al., 2009; Avelar et al., 2011; Coelho Netto et al., 2011; Marques et al., 2018) e, mais recentemente, no município de Itaoca (São Paulo) (Gramani, Arduin, 2015; Matos et al., 2018).

Este quadro pode ser um reflexo direto da associação entre as características geomorfológicas e de uso da terra e os grandes volumes/intensidades pluviométricos responsáveis pela deflagração dos processos. Em grande parte destes eventos o volume e a intensidade das precipitações deflagraram simultaneamente escorregamentos rasos e profundos, em vertentes, e processos hidrodinâmicos como fluxos de detritos e inundações. Como consequência imediata, além das vítimas fatais, construções e edificações destruídas gerando irreversíveis danos ao patrimônio histórico e arquitetônico.

No verão de 2009-2010, os municípios situados no Planalto de Paraitinga-Paraibuna foram atingidos por precipitações prolongadas e intensas (Arguelo, 2016; Horta, 2017; Negrão et al., 2017; Stabile, Colângelo, 2017). Como consequência destas chuvas, inundações bruscas provocaram danos substanciais sobretudo nos centros urbanos e cerca de 2 mil escorregamentos foram deflagrados nas vertentes (Stabile, Colângelo, 2017). São Luiz do Paraitinga (Figura 1) foi um dos municípios mais atingidos, onde 5.163 pessoas foram afetadas (desabrigados, desalojados, deslocados e feridos), resultando em uma morte, 97 moradias destruídas, 134 moradias e seis edifícios públicos danificados, $220 \mathrm{~km}$ vias urbanas danificadas, além de 80 pontes destruídas, um prejuízo estimado em $\mathrm{R} \$ 141$ milhões (Brollo et al., 2010; Gomes, Gramani, 2010; Pellegrina, 2011). 

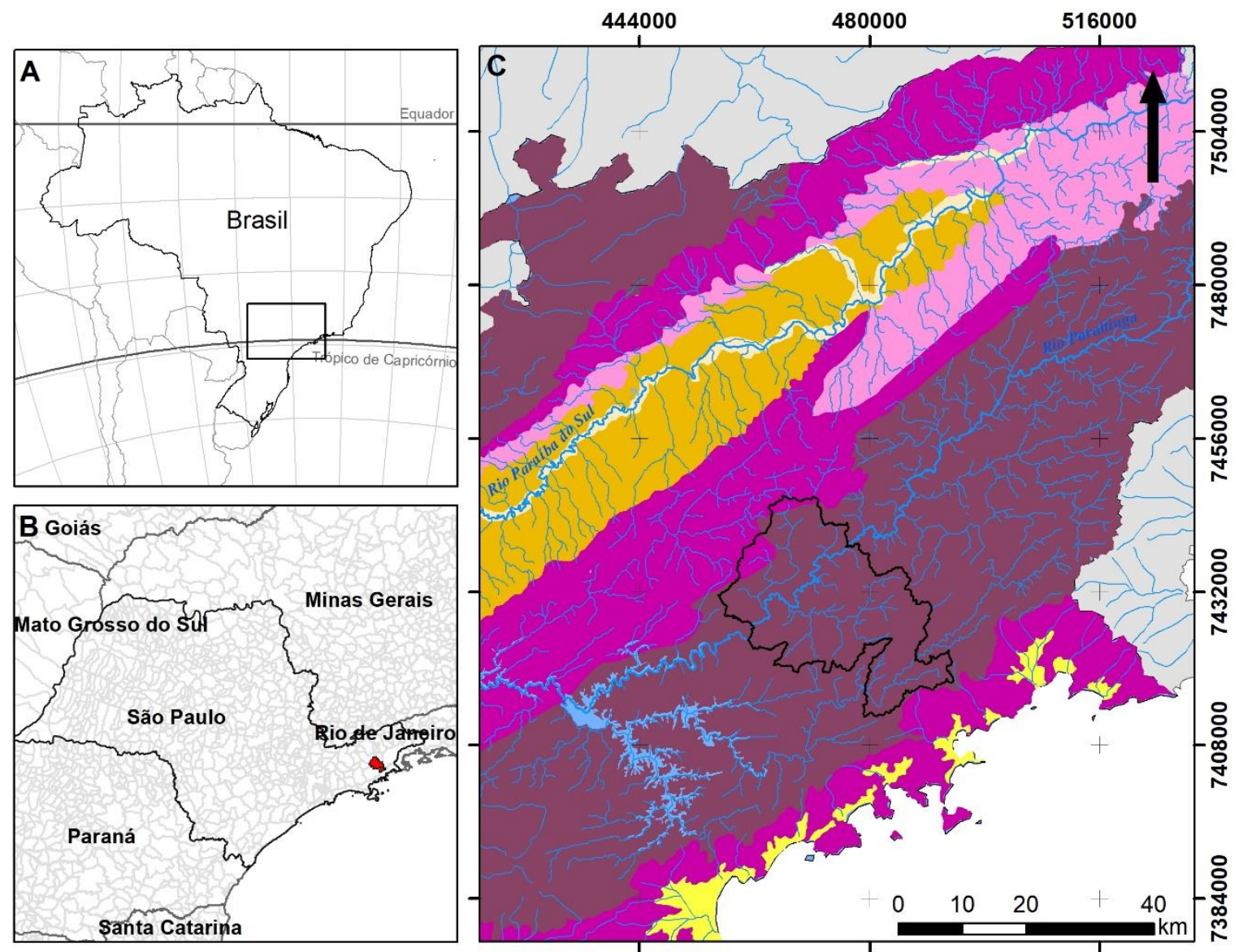

\section{Legenda}

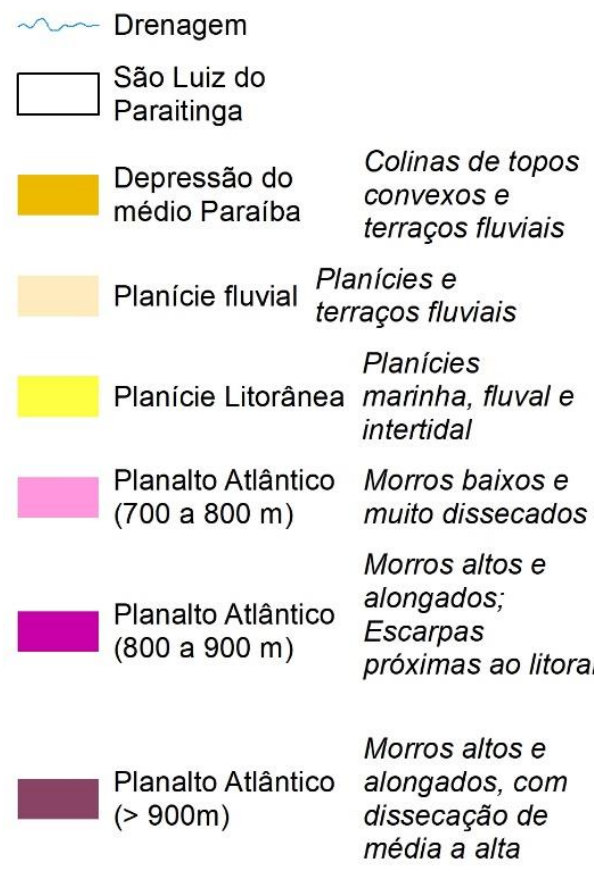

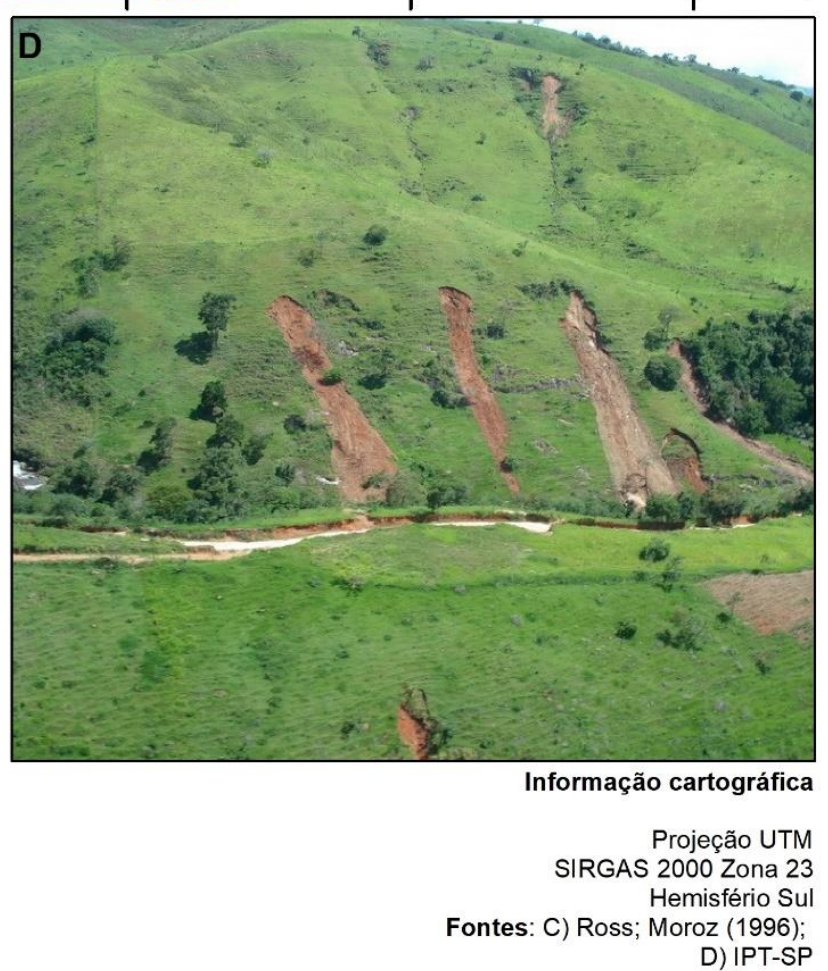

Figura 1: Localização e mapa geomorfológico da área de estudo. (A) Localização da área de estudo no Brasil e (B) no Estado de São Paulo: (C) Geomorfologia da região do médio Vale do Paraíba do Sul; (D) Escorregamentos deflagrados no verão de 2009-2010 em São Luiz do Paraitinga.

Fontes: C) Ross e Moroz (1996); D) Instituto de Pesquisas Tecnológicas do Estado de São Paulo 
Assim, o objetivo deste artigo foi caracterizar as áreas afetadas por escorregamentos, considerando suas características geológicas, geomorfológicas e de uso da terra no Vale do Paraitinga, encerrado no Planalto do Paraitinga-Paraibuna.

\section{O Rio Paraitinga e o Evento 2009-2010}

O Rio Paraitinga forma uma bacia hidrográfica que se estende por $2.380 \mathrm{~km}^{2}$, no estado de São Paulo e abriga diversos municípios, sendo que alguns conservam um patrimônio arquitetônico que remonta ao período colonial do Brasil, como Cunha e São Luiz do Paraitinga.

Dentre os municípios que evoluíram na região, São Luiz do Paraitinga (Figura 2), fundado em 1769 às margens do rio homônimo, surgiu em função de sua localização ao longo da rota de escoamento da produção aurífera de Minas Gerais, a chamada Estrada Real (Petrone, 1959; Santos, 2006; Verde, 2013).

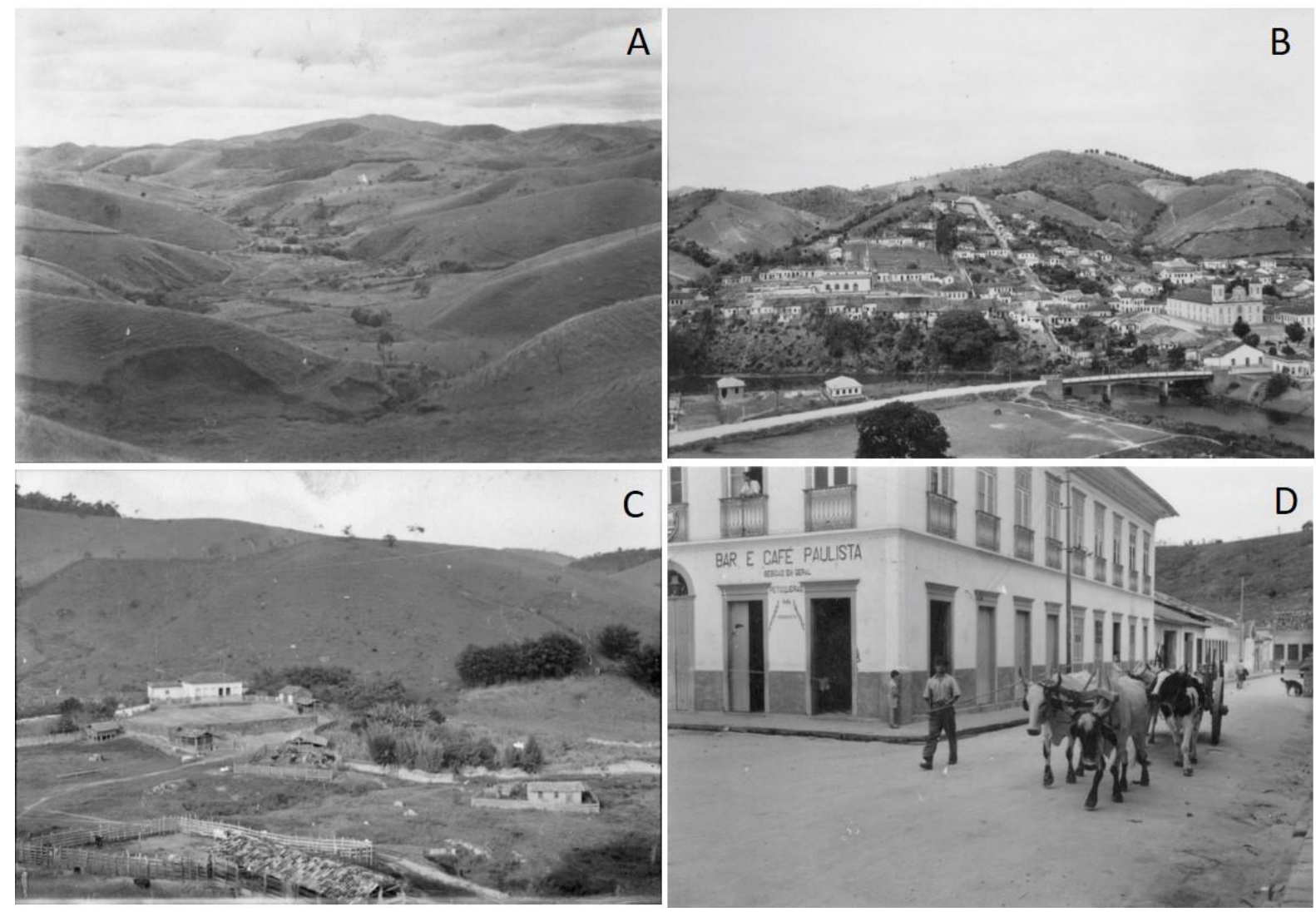

Figura 2: São Lioz do Paraitinga na década de 1950. A) Típica paisagem do Vale do Rio Paraitinga (nota-se a ausência de vegetação florestal; B) A cidade de São Luiz do Paraitinga às margens do Rio (a Igreja Matriz São Luíz de Tolossa a direita na foto); C) Fazenda no Vale do Paraitinga (verifica-se a área de secagem de café em frente à sede); D) Carro de Boi na cidade e típico casario do período colonial.

Fonte: IBGE, sendo A, B e D de Nilo Bernardes e Tibor Jablonsky em 1955 e C de Antônio Teixeira Guerra e Tibor Jablonsky em 1958. 
O município abriga expressivo patrimônio arquitetônico do período colonial brasileiro, como a Capela Nossa Senhora das Mercês, o Mercado Municipal, a Igreja Matriz São Luíz de Tolossa, além do casario na área central (Santos, 2016). Em 1982 seu Centro Histórico foi tombado pelo Conselho de Defesa do Patrimônio Histórico, Arqueológico, Artístico e Turístico do Estado de São Paulo (CONDEPHAAT).

As mudanças no uso e ocupação da terra se intensificam no século XIX, marcado por uma aceleração no desmatamento da vegetação primária (floresta ombrófila densa de formação montana) para a expansão da monocultura de café, assim como ocorreu em outras áreas da região do Vale do Paraíba do Sul, a qual integra o Rio Paraitinga (Petrone, 1959; Santos, 2006; Verde, 2013).

Com o declínio da monocultura cafeeira no início do século XX, houve uma conversão gradual das lavouras de café para o desenvolvimento da pecuária de gado leiteiro, com ampliação do desmatamento (Petrone, 1959; Verde, 2013). A partir da década de 1970, se inicia a substituição de parte dos pastos para plantações de eucaliptos destinados à produção de celulose, processo que se intensifica entre os anos de 2000 e 2010 (Brollo et al., 2010; Correa et al., 2015).

Um outro fato de destaque na região é a ocorrência de enchentes e inundações com repercussão na área urbana, como os eventos de 1863 , no qual as águas do rio alcançaram a escadaria da igreja matriz, além de 1967, 1971 e 1996 (Campos, 2011; Marchezini et al., 2018). Entre os anos de 2000 e 2006 também ocorreram dois eventos de inundação que atingiram o centro urbano (Brollo et al., 2008). Entretanto, o episódio de maior repercussão ocorreu entre Dezembro de 2009 e Janeiro de 2010, tendo sido registrado, no mês de Dezembro, um acumulado de precipitação de $625,5 \mathrm{~mm}$, com valores de $112 \mathrm{~mm} / 24 \mathrm{~h}$ no dia 3/12/2009 (Horta, 2017) o que, além de inundar a área urbana, deflagrou inúmeros escorregamentos nas cabeceiras e anfiteatros à montante da cidade. Na madrugada entre os dias 31/12/2009 e 01/01/2010 ocorreu uma acentuada precipitação (Figura 3), havendo registros de até $50 \mathrm{~mm} / \mathrm{h}$ em determinadas áreas dos municípios de São Luiz do Paraitinga, Lagoinha e Cunha (Stabile, Colângelo, 2017) e estimado um excedente de $100 \mathrm{~mm}$ entre os dias 28 de dezembro e 01 de janeiro acima da média climatológica (CPTEC, 2010).

Neste evento o Rio transbordou 11 metros acima de seu nível normal, o maior já registrado no município, alcançando a área central da cidade que abrigava 437 imóveis dos séculos XVIII e XIX, tombados pelo patrimônio histórico, levando à danos ao patrimônio arquitetônico, como o desabamento da Igreja Matriz e severos danos à inúmeras edificações (Brollo et al., 2008; Brollo et al., 2010) (Figura 4). Em 2008 o Instituto Geológico do Estado de São Paulo já havia mapeado 18 setores de risco a escorregamentos e 13 setores de risco a inundações. Posteriormente ao evento foram mapeadas 16 áreas de risco no município, a exemplo das imediações da praça da matriz, classificada como Risco Muito Alto (Gomes, Gramani, 2010). 


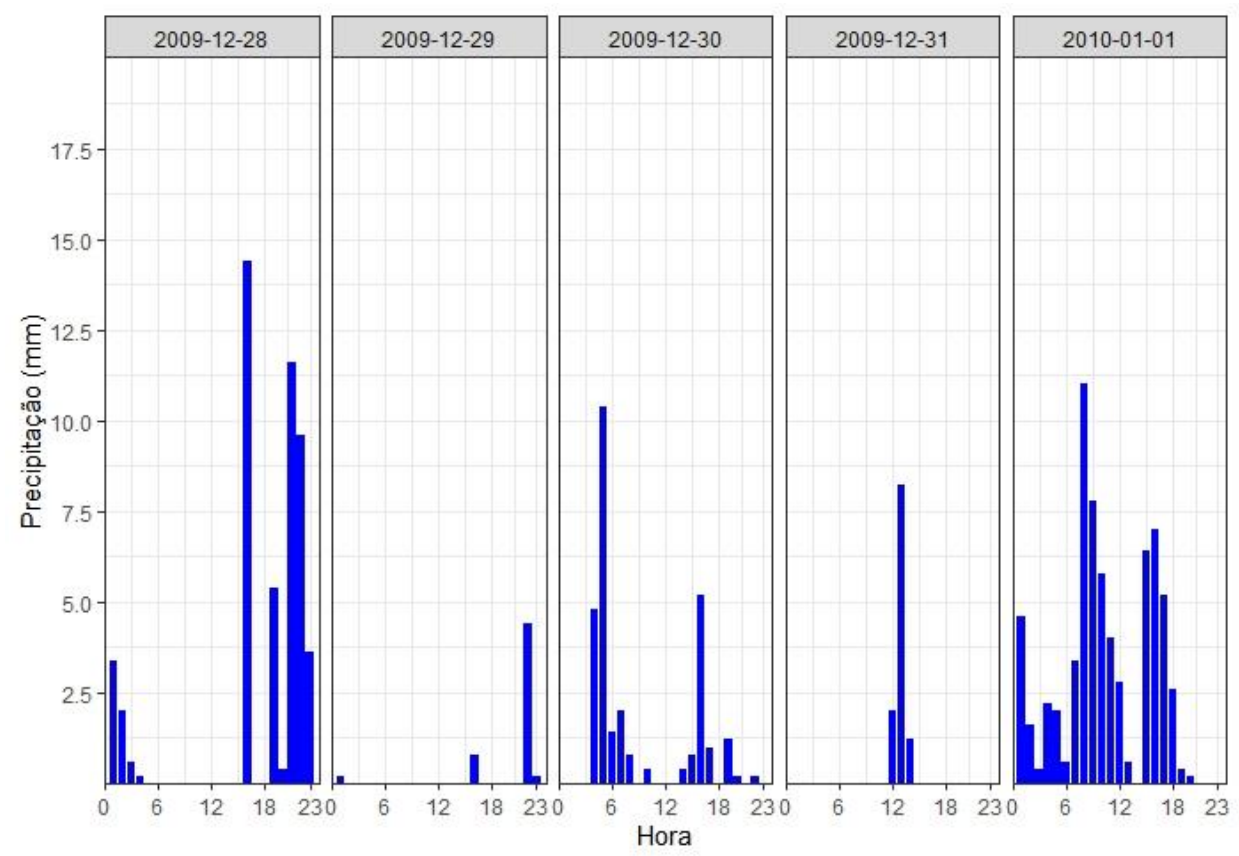

Figura 3: Precipitação horária entre os dias 28 de Dezembro de 2009 e 01 de Janeiro de 2010 na estação automática São Luiz do Paraitinga (2345065).

Fonte: Instituto Nacional de Meteorologia (INMET).
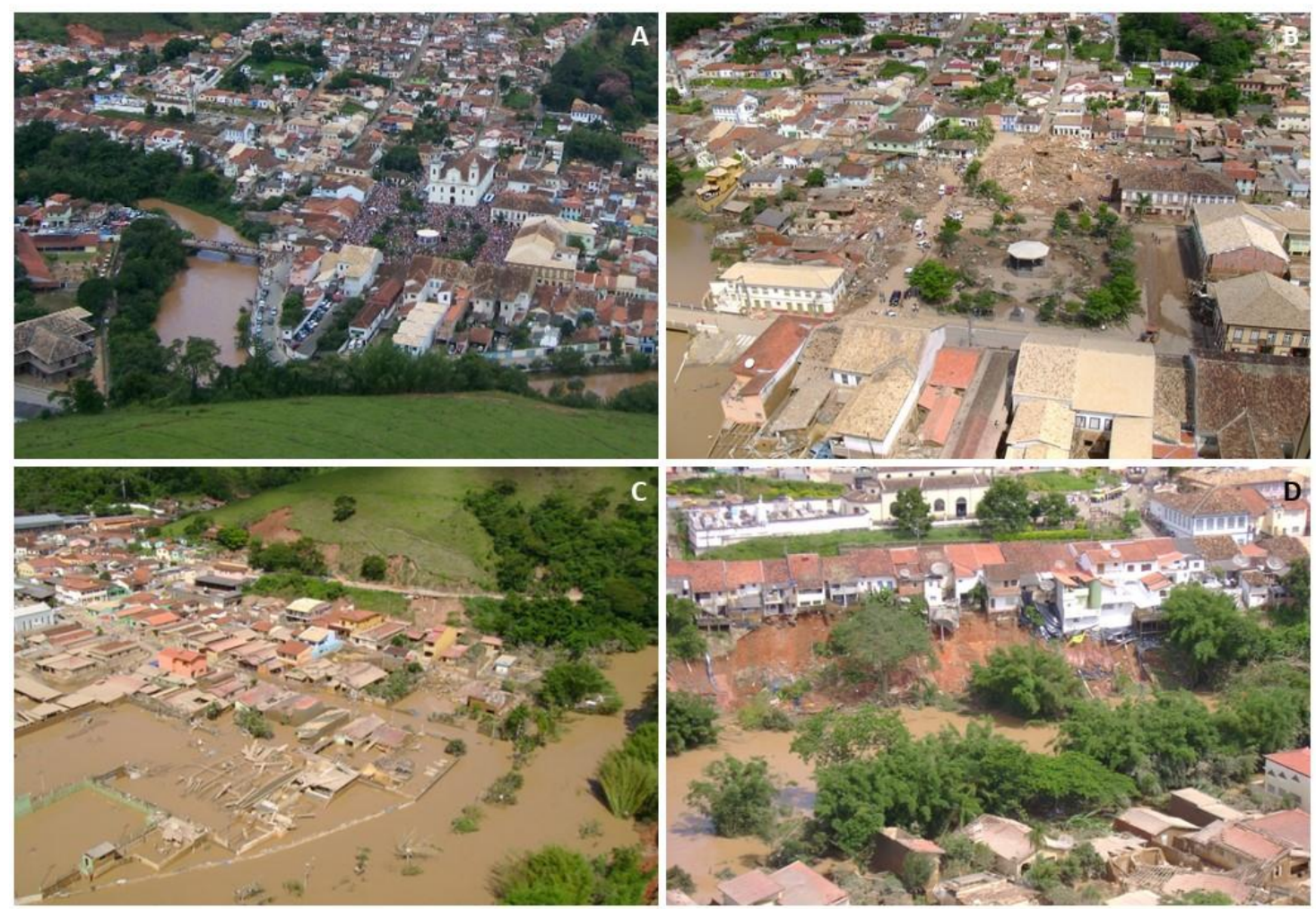

Figura 4: Fotografias do desastre de 2009-2010 em São Luiz do Paraitinga. Praça central e a Igreja matriz antes (A) e depois (B) da inundação de 2009-2010; Bairro alagado (C) e rompimento de taludes (D) na área urbana do município.

Fonte: Instituto de Pesquisas Tecnológicas do Estado de São Paulo (IPT-SP). 


\section{Caracterização Geológico-Geomorfológica dos Escorregamentos}

Para a caracterização geológico-geomorfológica dos escorregamentos foram selecionadas três bacias hidrográficas (Figura 5) que estão inseridas no Planalto Paraitinga-Paraibuna, que compõe a Unidade Morfoestrutural denominada Cinturão Orogenético Atlântico (Ross, Moroz, 1996); um sistema montanhoso originado por dobramentos e falhamentos tectônicos ao longo meso-cenozóico e orientação preferencial ENE a E-W, associada ao desenvolvimento do Rift Continental do Sudeste do Brasil (Riccomini et al., 2004).

O embasamento geológico mais amplo é composto por migmatitos homogêneos e heterogêneos com estrutura estromatítica, nebulítica e anatexítica, rochas granitoides de caráter intrusivo sintectônico, micaxistos e quartzo-micaxistos e uma zona de transição subordinada à intrusão granitoide e composta por rochas brechóides (Hasui, Bistrichi, et al., 1978; Hasui, Ponçano, et al., 1978). Predominam os cambissolos e neossolos litólicos com texturas argilo-arenosas variando entre 2-3 metros nos migmatitos e inferiores a $1 \mathrm{~m}$ nos granitoides (Hasui, Bistrichi, et al., 1978; Hasui, Ponçano, et al., 1978).

Nesta zona planáltica, se destacam as serras e escarpas da Quebra Cangalha (noroeste) e Paraitinga (sudeste) e o Gráben Paraitinga-Paraibuna (Figura 5). Este último delimitado pelas falhas de Santa Rita e Taxaquara, onde predominam colinas e morros baixos entre 400m e 700m (Gontijo-Pascutti et al., 2012). Ressalta-se também que este compartimento faz limite a nordeste com a Serra da Bocaina, onde se localizam as nascentes dos rios Paraitinga e Paraibuna (Gontijo-Pascutti et al., 2012; Ross, Moroz, 1996).

A Serra da Quebra Cangalha constitui um alto dissecado com elevações entre 800 e $1.000 \mathrm{~m}$, controlado localmente pelas falhas de Santa Rita e das Canas, já a Serra de Paraitinga, mais elevada e contínua, apresenta altitudes entre 900 e $1.100 \mathrm{~m}$ (Figura 6) (Gontijo-Pascutti et al., 2012; Hasui, Bistrichi, et al., 1978; Hasui, Ponçano, et al., 1978).

As três bacias hidrográficas selecionadas $\left(57 \mathrm{~km}^{2}\right)$ possuem 186 cicatrizes de escorregamentos deflagrados no evento de 2009-2010, aproximadamente $33 \%$ do total de cicatrizes mapeadas (567 cicatrizes) (CPRM, IPT S/A, 2014; Oliveira et al., 2018). 


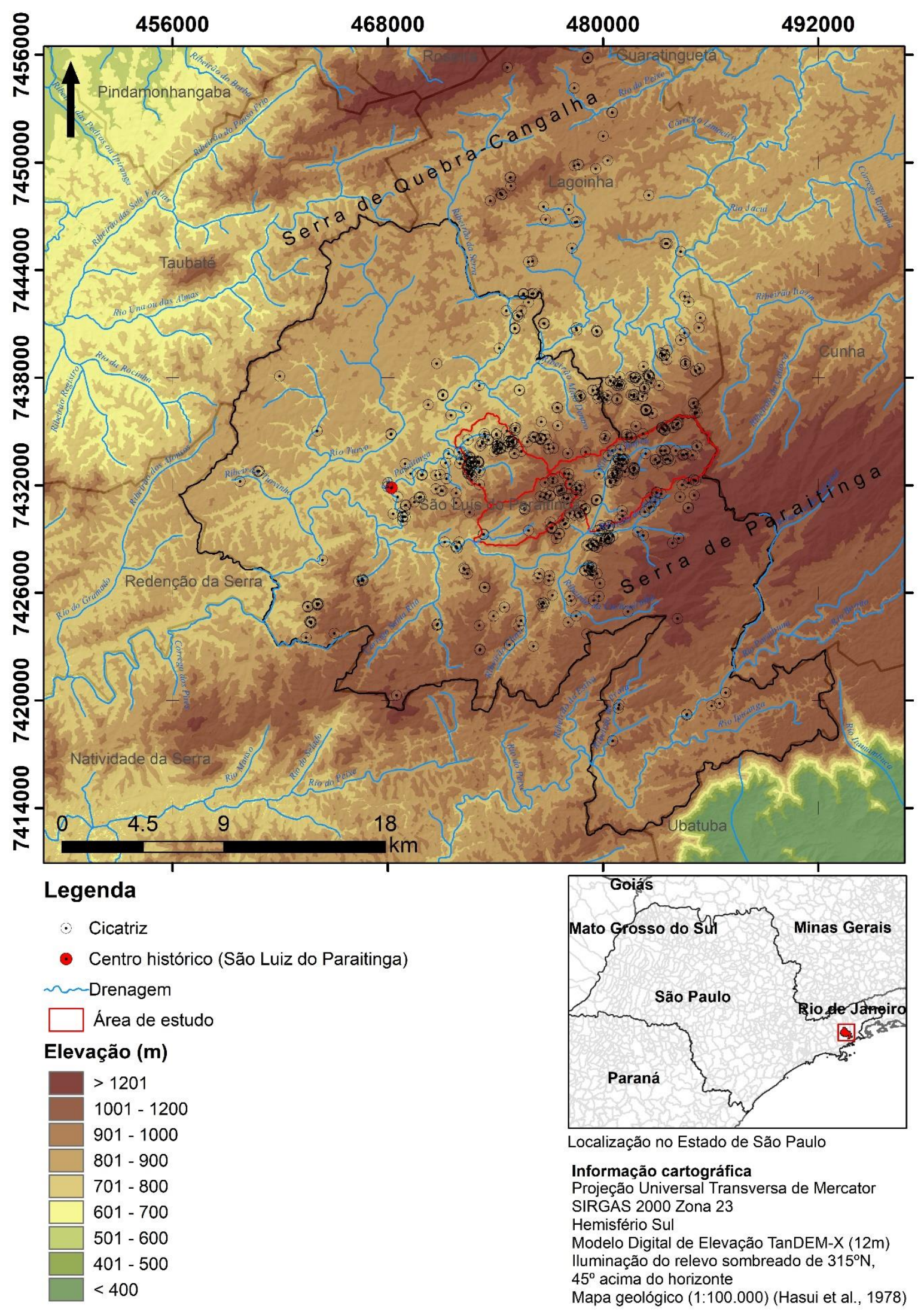

Figura 5: Mapa de localização das bacias selecionadas e hipsometria. 


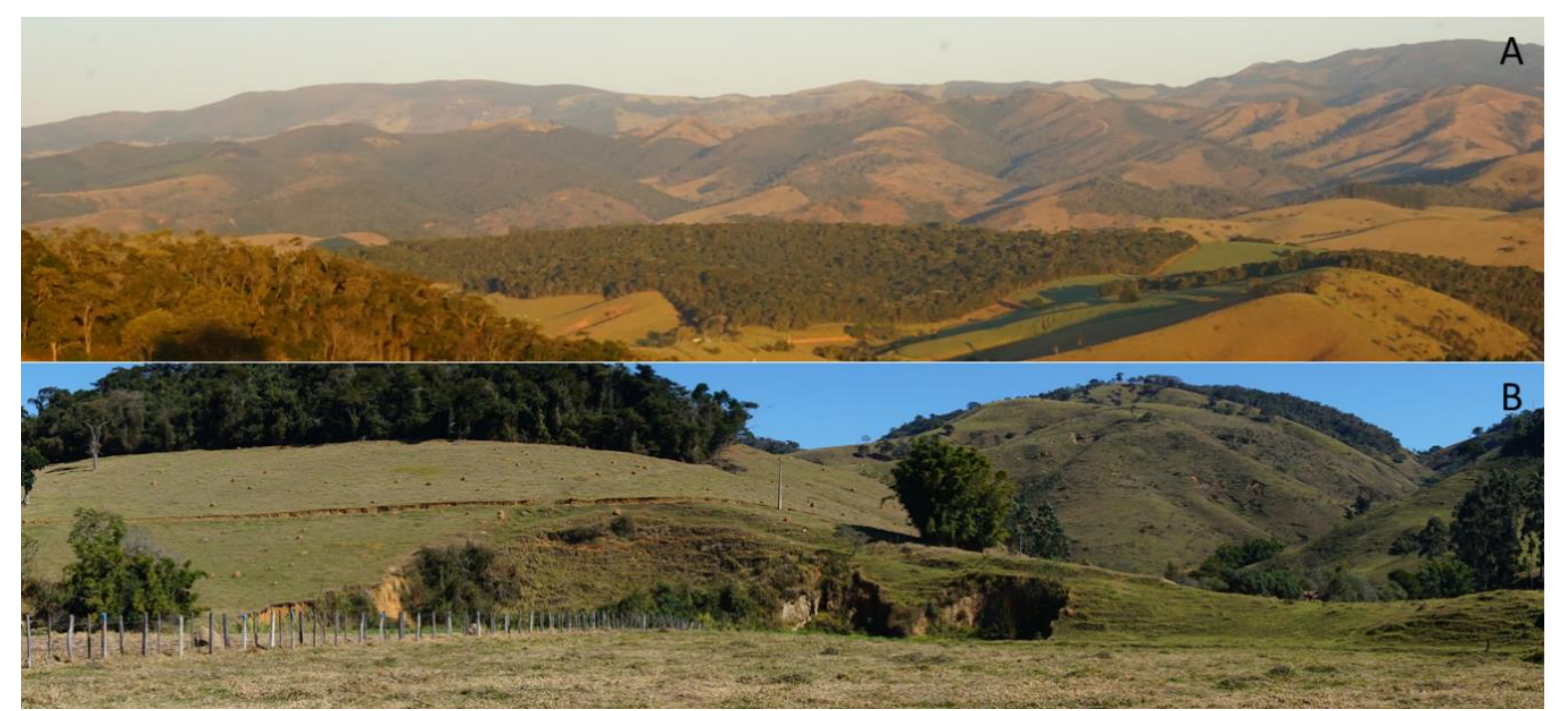

Figura 6: Formas de relevo do Planalto de Paraitinga-Paraibuna. Vista geral das formas do relevo em São Luiz do Paraitinga (SP) (A); Colinas e vertentes recobertas por pastagens em São Luiz do Paraitinga (B).

Nestas bacias, a maior parte das vertentes possui ângulos até $23^{\circ}$, com curvatura côncava (planta e perfil) e cobertas sobretudo por pastos, tipo de uso predominante no município (Brollo et al., 2010), frequentemente com terracetes de pisoteio de gado. Neste contexto, as cicatrizes de escorregamentos ocorreram, em sua maioria, em vertentes com ângulos entre $25^{\circ}$ e $37^{\circ}$, com maior concentração entre $30^{\circ}$ e $37^{\circ}$ (55.1\%), classe que perfaz uma área de apenas $8.3 \%$ das bacias (Figuras 7A e $8 \mathrm{~A}$ ). A maior parte destas vertentes íngremes afetadas por escorregamentos possui cobertura da terra do tipo pasto e com grande quantidade de terracetes de pisoteio de gado, características que podem auxiliar na explicação da maior quantidade de escorregamentos (Figura 9).

As áreas embasadas por rochas granitoides, que ocupam a maior área (60.7\%), registraram a maior quantidade de cicatrizes (51.9\%) (Figuras 7B e 8B). Outra parte expressiva das cicatrizes ocorreu nas áreas cujo embasamento são as rochas migmatíticas, principalmente metatexitos nebulíticos (28.1\%), que ocupam área muito menor que os granitoides. A maior ocorrência de escorregamentos nestes litotipos pode estar relacionada às características dos solos residuais derivados de sua alteração (por ex. espessura e coesão), e com outros fatores, tais como a distribuição espacial das precipitações que deflagraram os escorregamentos. 

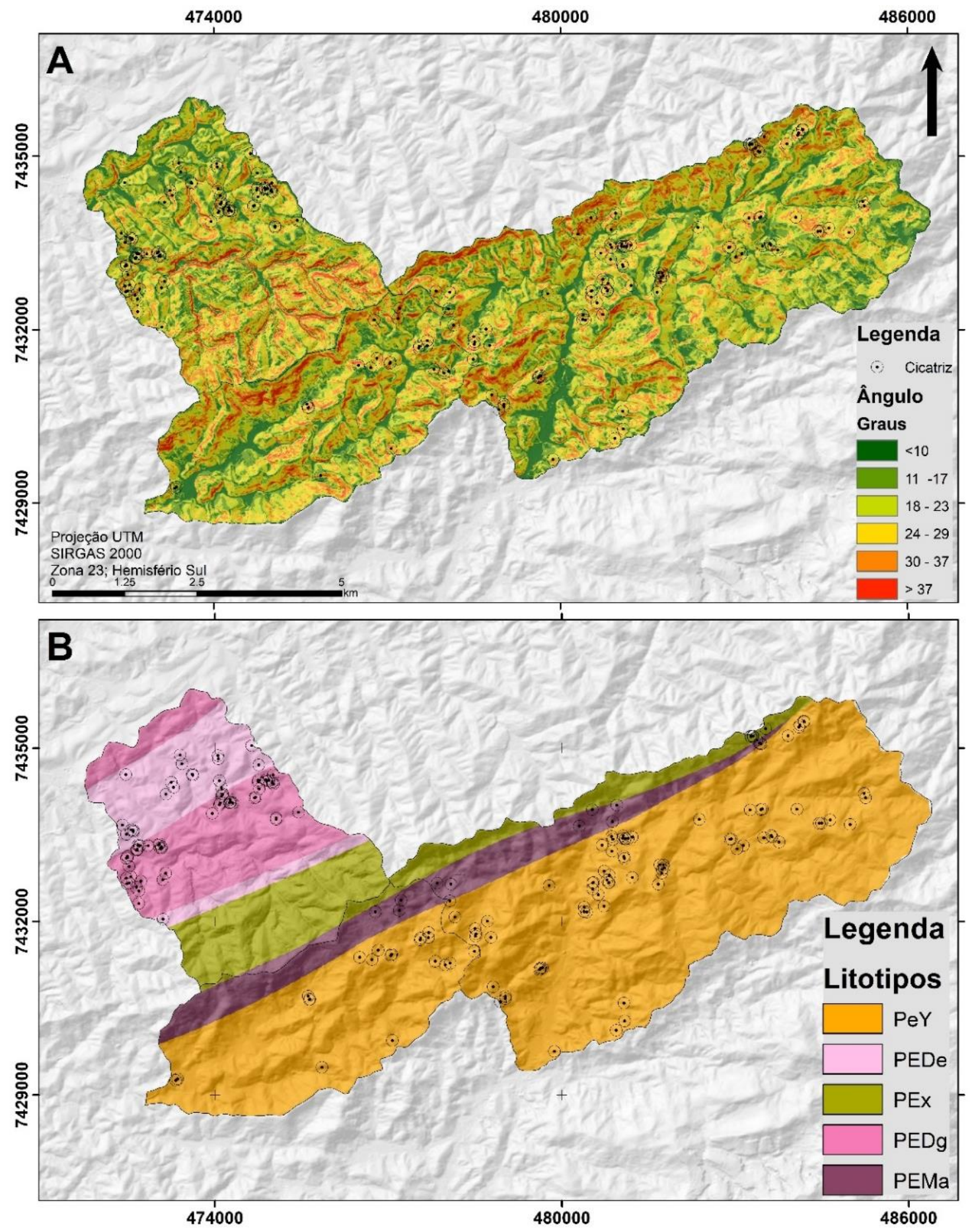

Figura 7: Mapas de ângulo das vertentes (A) e de litotipos (1:100.000) (B) (PeY - Granitoides; PEDe - Migmatitos homogêneos estromatíticos; Pex - Micaxistos; PEDg - Metatexito nebulítico; PEMa Faixa de Transição). 

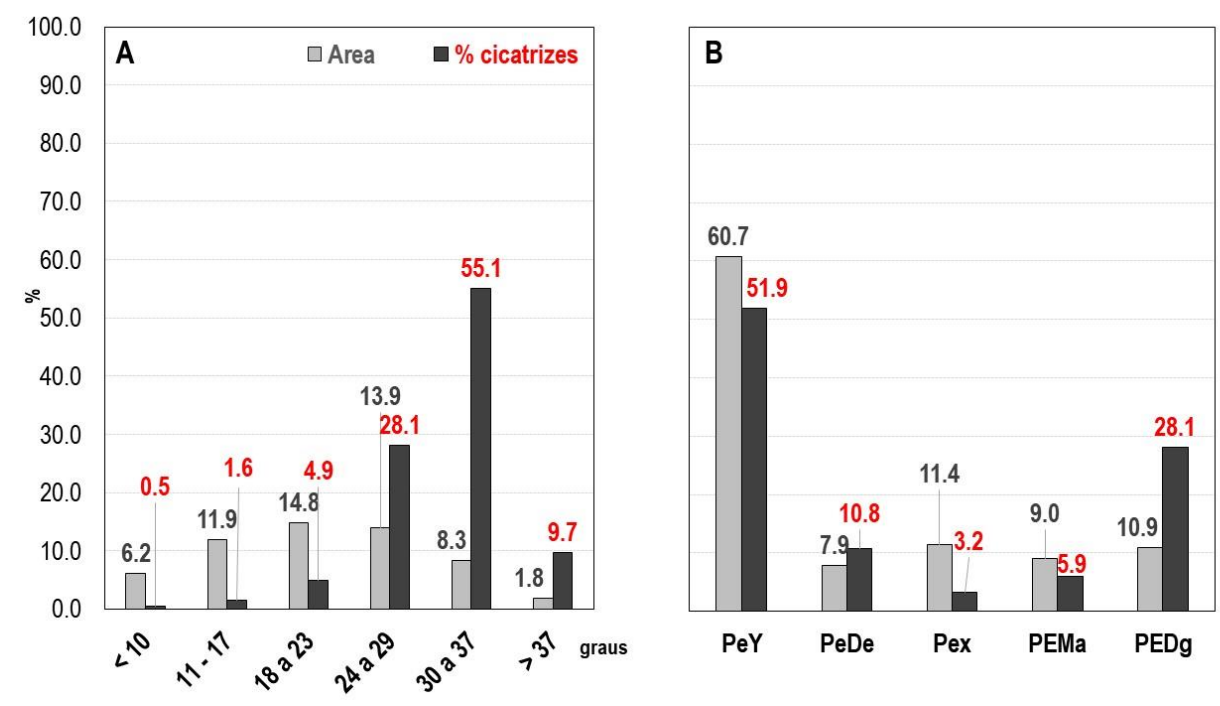

Figura 8: Gráficos de área das classes e percentual de cicatrizes de acordo com o ângulo da vertente

(A) e o litotipo (B) (PeY - granitoides; PeDe - migmatitos homogêneos estromatíticos; Pex micaxistos; PEMa - faixa de transição; PEDg - metatexito nebulítico.

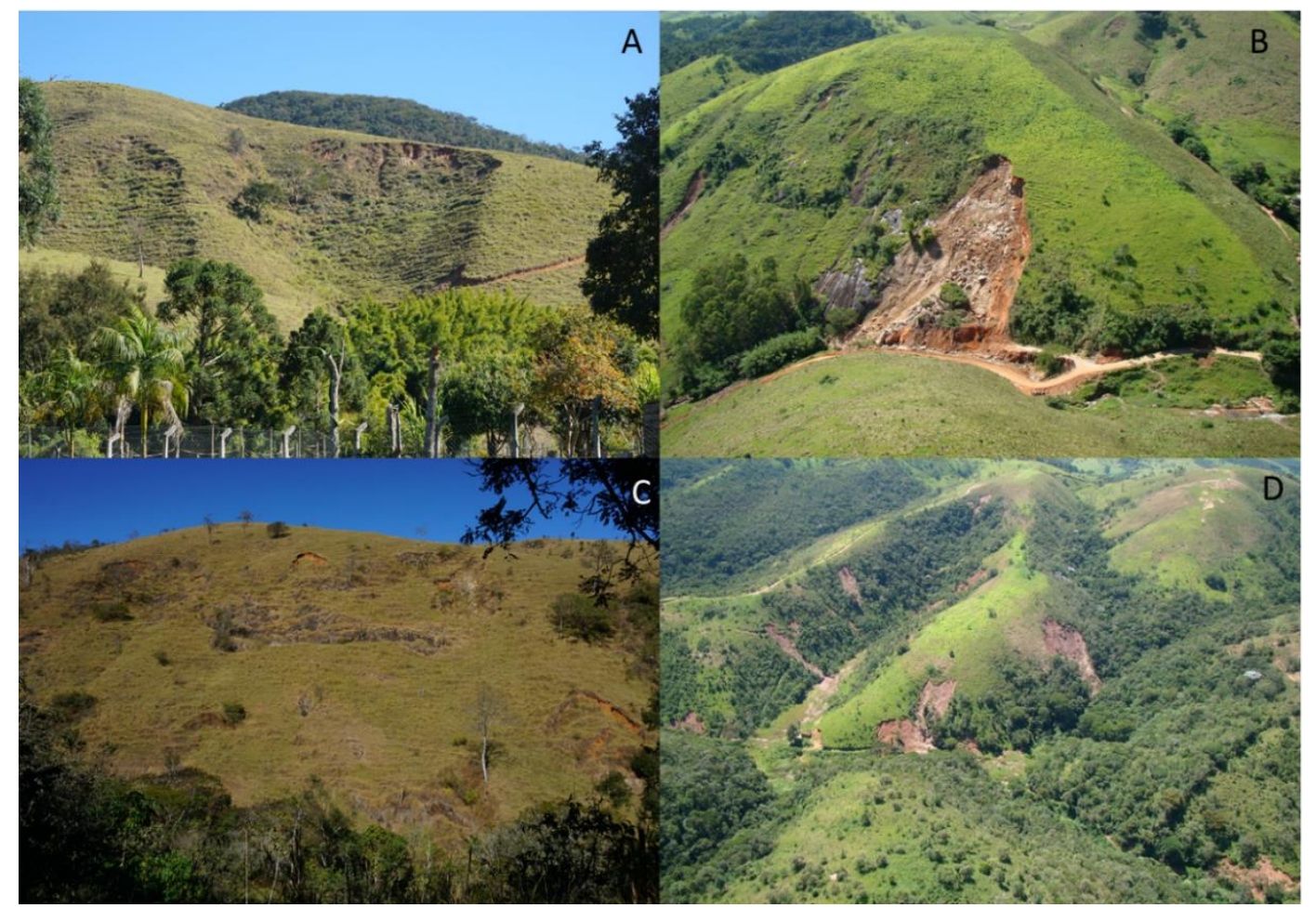

Figura 9: Escorregamentos rasos deflagrados em 2009-2010 em vertentes íngremes, com destaque para aqueles associados aos terracetes ( $\mathrm{A}$ e $\mathrm{C}$ ), em solos rasos (B) e em menor volume, mas com grandes dimensões em mata secundária (D).

Fonte: Instituto de Pesquisas Tecnológicas de São Paulo (fotos B e C).

\section{Conclusões}

Os escorregamentos de 2009-2010 ocorreram sobretudo em vertentes com ângulo entre $25^{\circ}$ e $37^{\circ}$ embasadas por granitoides e rochas migmatíticas, preferencialmente em cabeceiras côncavas em drenagem de primeira ordem. Em trabalhos futuros, a 
relação entre os pastos com terracetes de pisoteio e as vertentes côncavas poderá ser analisada em escala de maior detalhe, visando identificar suas influências sobre a ocorrência de escorregamentos na área. $\mathrm{Na}$ continuidade das pesquisas deverão estar incluídos levantamentos das características e tipologias de solos e dos volumes precipitados de chuvas para cada local especificamente. O refinamento das pesquisas permitirá identificar quais influências são determinantes sobre as ocorrências de escorregamentos na região do Planalto de Paraitinga-Paraibuna.

\section{Agradecimentos}

Os autores agradecem ao Conselho Nacional de Desenvolvimento Científico e Tecnológico (CNPq) pelo financiamento desta pesquisa de Mestrado, ao Programa de Pós-Graduação em Geografia Física (PPGF) da Universidade de São Paulo (USP) e aos colegas do Grupo de Pesquisas de Processos Morfodinâmicos e Ambientais da USP (GPmorfo-USP). Agradecem também ao Prof. Dr. Carlos H. Grohmann (IEEUSP) pelos dados de elevação TanDEM-X cedidos para este artigo, concedidos pelo German Aerospace Centre (DLR) (Announcement of Opportunity \& Proposal Call Proposal DEM_GEOL0538). Agradecem também aos revisores pelas contribuições ao artigo.

\section{Conflito de Interesses}

Os autores declaram que não têm qualquer conflito de interesse relativo a este artigo.

\section{Bibliografia}

Arguelo, F. V. P. (2016). Simulação hidrológica da bacia do rio Paraitinga para análise das potenciais causas do evento extremo de Cheia e desastre ocorrido na passagem de ano de 2009/2010. Dissertação de doutoramento, Instituto Nacional de Pesquisas Espaciais, São José dos Campos, Brasil.

Avelar, A. S., Netto, A. L. C., Lacerda, W. A., Becker, L. B., Mendonça, M. B. (2011). Mechanisms of the recent catastrophic landslides in the mountainous range of Rio de Janeiro, Brazil. In Landslide Science and Practice: Global Environmental Change, 4, 265270.

Barata, E. (1969). Landslides in the tropical region of Rio de Janeiro. In Proceeedings of the Seventh International Conference on Soil Mechanics and Foundation Engineering (pp. 507516), México.

Bigarella, J. J., Bigarella, I. E. K., Jost, H. C. (1975). Catastrophic events in the Tubarão area. Boletim Paranaense de Geociências, 33, 200-206.

Brollo, M J, Faria, D., Guedes, A., Ferreira, C., Rossini-Penteado, D., Armani, G., Santoro, J., Tominaga, L., Pressinotti, M. M. N., Fernandes-da-Silva, P., Ribeiro, R., Amaral, R. (2008). Mapeamento de áreas de risco associados a escorregamentos e inundações - Relatório Técnico - Município de São Luiz de Paraitinga. São Paulo: Instituto Geológico e CEDEC.

Brollo, M. J., Carlos, A., Guedes, M. (2010). Desastres Naturais e Riscos em São Luiz do Paraitinga (SP). In Anais do $7^{0}$ Simpósio Brasileiro de Cartografia Geotécnica e Geoambiental (pp. 1-19). Maringá: SBCGG. 
Campos, J. T. (2011). A Imperial São Luiz do Paraitinga: história, educação e cultura. Taubaté: Resolução Gráfica, 2011.

CEPED-UFSC. (2013). Atlas Brasileiro de Desastres Naturais 1991 a 2012 (2a ed.). Florianópolis: CEPED, Universidade Federal de Santa Catarina.

Coelho-Netto, A. L., Avelar, A. S., Lacerda, W. A. (2009). Landslides and Disasters in Southeastern and Southern Brazil. Developments in Earth Surface Processes, 13, 223-243. https://doi.org/10.1016/S0928-2025(08)10012-8

Coelho Netto, A. L., Sato, A. M., Souza, A. D. S., Vianna, L. G. G., Araújo, I. S., Ferreira, D. L. C., Lima, P. H., Silva, A. P. A., Silva, R. P. (2011). January 2011: The extreme landslide disaster in Brazil. Landslide Science and Practice: Risk Assessment, Management and Mitigation, 6, 377-384.

Correa, M. A., Carriello, F., Rodriguez, D. A. (2015). Análise da expansão da cultura de eucalipto no município de São Luiz do Paraitinga entre os anos de 2000 e 2015. In INPE (Org.), Anais do XIX Simpósio Brasileiro de Sensoriamento Remoto (pp. 347-350). São José dos Campos: INPE.

Costa Nunes, A. J. da. (1969). Landslides in soils of decomposed rocks due to intense rainstorms. In 7th International Conference on Soil Mechanics and Foundation Engineering (pp. 547-554). México.

CPTEC - Centro de Previsão do tempo e Estudos Climáticos. (2010). Infoclima - Boletim de Informações Climáticas do CPTEC/INPE, ano 17, n.1. São José dos Campos: CPTEC/INPE.

De Ploey, J., Cruz, O. (1979). Landslides in the Serra do Mar, Brazil. Catena, 6(2), 111-122. https://doi.org/10.1016/0341-8162(79)90001-8

EM-DAT - Emergency Events Database (2020). OFDA/CRED. The Office of Foreign Disaster Assistance/Centre for Research on the Epidemiology of Disasters. https://public.emdat.be/

Gomes, L. A., Gramani, M. F. (2010). Relato de vistoria técnica - São Luís do Paraitinga.

Gontijo-Pascutti, A. H. ., Hasui, Y., Santos, M., Junior, A. V. S., Souza, I. A. (2012). As Serras do Mar e da Mantiqueira. In A. Hasui, Yociteru; Carneiro, C. D. R; Almeida, F. F. M.; Bartorelli (Org.), Geologia do Brasil (pp. 549-571). São Paulo: Editora Beca.

Gramani, M. F., Arduin, D. H. (2015). Morfologia da drenagem e dos depósitos de debris flow em Itaóca, São Paulo. In ABGE (Coord) Anais do 15ํㅡㄴ Congresso Brasileiro de Geologia de Engenharia e Ambiental (pp. 1-10). Bento Gonçalves, ABGE.

Hasui, Y., Bistrichi, C. A., Carneiro, C. D. R., Stein, D. P., Melo, M. S., Pires Neto, A. G., Ponçano, W. L., Almeida, E. B., Siracuza, J. R., Abreu, A. C. S., Frangipani, A., Prandini, F. L., Iwasa, O. Y. (1978). Geologia da Folha de São José dos Campos - SP, SF-23-Y-D-II (Anexo mapa geológico em escala 1:100.000). São Paulo: Instituto de Pesquisas Tecnológicas do Estado de São Paulo S/A - IPT.

Hasui, Y., Ponçano, W. I., Bistrichi, C. A., Stein, D. P., Galvão, C. A., Gimenez, A. F., Almeida, M. A., Pires Neto, A. G., Melo, M. S., Santos, M. C. S. R. (1978). Geologia da Região Administrativa 3 (Vale do Paraíba) e parte da Região Administrativa 2 (Litoral) do Estado de São Paulo. São Paulo: Instituto de Pesquisas Tecnológicas do Estado de São Paulo S/A - IPT. 
Horta, I. T. L. G. (2017). Análise de impactos pluviais em São Luiz do Paraitinga - SP/Brasil. Dissertação de mestrado, Universidade de São Paulo, São Paulo, Brasil.

Jones, F. O. (1973). Landslides of Rio de Janeiro and the Serra das Araras Escarpment, Brazil. Geological Survey Professional Papers, 697. Washington: United States Geological Survey. https://doi.org/10.3133/pp697

Marchezini, V., T., R., Conceição, R. S., Mendes, T. S. G., Negri, R. G. (2018). Desafios para uma agenda de prevenção de desastres em sítios históricos: o caso de São Luiz do Paraitinga, SP. Patrimônio e Memória, 14, 2, 375-400.

Marques, M. C. D. O., Coelho Netto, A. L., Sato, A. M. (2018). Influência de floresta secundária e gramínea na deflagração de deslizamentos translacionais rasos em Nova Friburgo, Rio de Janeiro. Revista Brasileira de Geomorfologia, 19(4), 793-806. http://dx.doi.org/10.20502/rbg.v19i4.1479

Martins, T. D., Oka-Fiori, C., Vieira, B. C., Bateira, C. V. M., Montgomery, D. R. (2017). Avaliação de MDT na modelagem de instabilidade de vertentes. RA'EGA - O Espaco Geografico em Análise, 41, 07-19. http://dx.doi.org/10.5380/raega.v41i0.47607

Massad, F., Cruz, P. T., Kanji, M. A. E., Araújo Filho, H. A. (2000). Characteristics and volume of sediment transported in debris flows in Serra do Mar, Cubatão, Brasil. Proceedings of the International Workshop on Debris Flow Disaster. Venezuela: Caracas.

Matos, L. D. J., Ferreira, C. J., Bateira, C. V. de M., Vieira, B. C. (2018). Avaliação das Construções Danificadas por Corridas de Detritos e Inundações Bruscas no Vale do Ribeira (SP) em 2014. Revista do Departamento de Geografia, Especial, 57-67. https://doi.org/10.11606/rdg.v0ispe.144423

Negrão, A. C., Rodriguez, D. A., Chou, S. C., Medeiros, G. S., Siqueira Junior, J. L., Camargo, C. P. (2017). Previsão de vazão de eventos extremos utilizando o modelo hidrológico distribuido MHD-INPE e previsões meteorológicas do modelo ETA-INPE para uma alta resolução espacial - Estudo de caso: São Luiz do Paraitinga (SP). Revista Brasileira de Cartografia, 69(4), 647-657.

Oliveira, M. R. P. de, Vieira, B. C., Ross, J. L. S. (2018). Suscetibilidade Morfológica e Geológica aos Escorregamentos no Planalto de Paraitinga-Paraibuna (SP). Revista do Departamento de Geografia, Especial, 93-106. https://doi.org/10.11606/rdg.v0ispe.148486

Oliveira, J. R. R. (2016). Redução de risco de desastres e desenvolvimento sustentável. In Coordenadoria Estadual de Proteção e Defesa Civil de São Paulo (CEPDC-SP) (Org.), Redução de risco de desastres: Uma construção de resiliência local (p. 13-26). São Paulo: Imprensa Oficial.

Pellegrina, G. (2011). Proposta de um procedimento metodológico para o estudo de problemas geoambientais com base em banco de dados de eventos atmosféricos severos. Dissertação de mestrado, Universidade Estadual Paulista, Bauru, Brasil.

Petrone, P. (1959). A região de São Luiz do Paraitinga. Revista Brasileira de Geografia, 21(3), 3-99.

Riccomini, C., Sant'Anna, L. G., Ferrari, A. I. (2004). Evolução Geológica do Rift Continental do Sudeste do Brasil. In B. B. Mantesso-Neto, V.; Bartorelli, A.; Carneiro, C .D. R.; BritoNeves (Orgs.), Geologia do Continente Sul Americano: Evolução da Obra de Fernando Flávio Marques de Almeida. (p. 383-405). São Paulo: Editora Beca. 
Ross, J. L. S., Moroz, I. C. (1996). Mapa Geomorfológico do Estado de São Paulo. Revista do Departamento de Geografia, 10, 41-58. https://doi.org/10.7154/RDG.1996.0010.0004

Santos, C. M. (2016). Memórias e formas urbanas: a reconstrução do núcleo urbano de São Luiz do Paraitinga e a preservação do seu patrimônio cultural. Boletim Campineiro de Geografia, 6(2), 385-406.

Santos, C. M. P. (2006). O reencantamento das cidades: Tempo e Espaço na memória do patrimônio cultural de São Luiz do Paraitinga/SP. Dissertação de mestrado, Universidade Estadual de Campinas, Campinas. Brasil.

Serviço Geológico do Brasil - CPRM, Instituto de Pesquisas Tecnológicas - IPT S/A. (2014). Carta de Suscetibilidade a Movimentos Gravitacionais de Massa e Inundações - Município de São Luís do Paraitinga/SP. Escala 1:50.000.

Silveira, C. T. da, Fiori, A. P., Ferreira, A. M., Felipe, R. D. S., Kepel Filho, J. L., Folador, R. M., Costa, L. C. (2013). Análise do Fator de Segurança da estabilidade das vertentes na bacia do rio Jacareí, Serra do Mar Paranaense. Revista Brasileira de Geomorfologia, 13(3), 287-297. http://dx.doi.org/10.20502/rbg.v13i3.224

Stabile, R. A., Colângelo, A. C. (2017). Estudo pluviométrico dos escorregamentos deflagrados no verão de 2009/2010 no planalto do Paraitinga (SP). In A. Perez Filho, R. R. Amorim (Org) Os Desafios da Geografia Física na Fronteira do Conhecimento (p. 38783889). Campinas: Universidade Estadual de Campinas.

Tatizana, C., Ogura, A. T., Cerri, L. E. S., Rocha, M. C. M. (1987). Análise da correlação entre chuvas e escorregamentos na Serra do Mar, município de Cubatão. In Anais do $5^{\circ}$ Congresso Brasileiro de Geologia de Engenharia (pp. 225-236). São Paulo: ABGE.

Verde, P. F. (2013). Cidades históricas atingidas por tragédia ambiental: estudo de caso de São Luís do Paraitinga (SP). Dissertação de mestrado, Pontifícia Universidade Católica de Campinas, Campinas, Brasil.

Vianna, L. F. N. (2009). Relatório sobre o levantamento dos deslizamentos ocasionados pelas chuvas de novembro de 2008 no complexo do Morro do Baú, municípios de Ilhota, Gaspar e Luiz Alves. Florianópolis: Epagri, 2009.

Wolle, C. M., Hachich, W. (1989). Rain-induced landslides in Southeastern Brazil. In Proceedings of the 12th International Conference on Soil Mechanics and Foundation Engineering (pp. 1639-1642). Rio de Janeiro.

Artigo recebido em / Received on: 23/10/2020

Artigo aceite para publicação em / Accepted for publication on: 18/12/2020 
Bonini et al. / Physis Terrae, Vol. 2, no 2, 2020, 85-99

Página intencionalmente deixada em branco 